\title{
Rapid detection of several endangered agarwood-producing Aquilaria species and their potential adulterants using plant DNA barcodes coupled with high-resolution melting (Bar-HRM) analysis
}

\begin{abstract}
Aquilaria is an endangered agarwood-producing genus that is currently protected by international laws. The agarwood trade is strictly monitored to prevent illegal harvesting, which has caused high demand for this natural product. Other plant sources of similar appearance or fragrance as agarwood are used as adulterant species in counterfeit products. To promote species identification via the DNA barcoding technique, the existing DNA barcoding database in our laboratory was enriched with seven plant barcoding sequences from a commercially important Aquilaria species (Aquilaria beccariana) and seven adulterant species (Cocos nucifera, Dalbergia latifolia, Pinus contorta var. latifolia, Santalum album, Strychnos ignatii, Thuja sp. and Terminalia catappa). DNA barcoding with highresolution melting analysis (Bar-HRM) showed that the mini-barcode internal transcribed spacer 1 (ITS1) was an effective gene locus that allows for a rapid and species- specific detection of Aquilaria and their adulterants, while four other mini-barcodes ( $\operatorname{rbc} \mathrm{L}, \operatorname{trn} \mathrm{L}$ intron, ITS2 and 5.8s) functioned as a support and a crosscheck for the barcoding results. The accuracy of the Bar-HRM technique in species origin identification was further assessed with seven agarwood blind specimens. The Bar-HRM technique is a potential tool for validating agarwood-species origin and detecting products with adulterant species.
\end{abstract}

Keyword: Mini-barcodes; Neighbor-joining tree; Species authentication; Thymelaeaceae; Wood forensics 